\title{
First links between self-feeding behaviour and personality traits in European seabass, Dicentrarchus labrax
}

\author{
Ferrari Sebastien ${ }^{1,4,{ }^{*}}$, Benhaïm David ${ }^{3}$, Colchen Tatiana ${ }^{1}$, Chatain Beatrice ${ }^{2,4}$, Bégout Marie-Laure ${ }^{1}$ \\ ${ }^{1}$ Ifremer, Place Gaby Coll, BP7, 17137 L'Houmeau, La Rochelle, France \\ ${ }^{2}$ Station Expérimentale d'Aquaculture Ifremer, Laboratoire de Recherche Piscicole de Méditerranée, \\ Chemin de Maguelone, 34250 Palavas-Les-Flots, France \\ ${ }^{3}$ Cnam/Intechmer, BP 324, 50103 Cherbourg Cedex, France \\ ${ }^{4}$ UMR 110 INTREPID, Ifremer-Cirad, 34000 Montpellier, France \\ * Correponding author : Sébastien Ferrari, tel.: +33 546500611 ; email address : sebferrari@hotmail.fr
}

\begin{abstract}
:
Most studies carried out with seabass under self-feeding conditions report an intriguing social structure that is built around the device and the food dispenser with three coexisting triggering categories: hightriggering $(\mathrm{HT})$, low-triggering $(\mathrm{LT})$ and zero-triggering $(\mathrm{ZT})$ fish. However, neither sex nor feeding motivation or hierarchy can explain the establishment of this specialization. We characterised the personality of seabass with the commonly used restraint and open field tests and assessed the link between personality traits and individual triggering activity towards the self-feeder apparatus. We found no differences between triggering categories during the restraint test but high triggering fish were characterised as shyer than low- and zero-triggering fish during the open field test. Triggering activity was negatively correlated with exploratory capacities and boldness. This experiment provides for the first time evidence that high triggering status in seabass is correlated with personality traits, which could partly explain the social structure that builds around a self-feeder device.
\end{abstract}

\section{Highlights}

European seabass personality (i.e. bold-shy and motivation to escape stressful situation) was characterized. Latency to emerge from a shelter and latency to escape during a restraint test were correlated. Placed under self-feeding, individual triggering activity level was higher in shy individuals.

Keywords : Behaviour, Boldness, Foraging, Open field test, Restraint test, Teleost 


\section{Introduction:}

Self-feeder devices have been widely used with Teleost fish (Covès et al., 2006). They have been developed primarily to allow fish to obtain food according to their nutritional needs, resulting in more robust growth, lower food wastage (Covès et al., 2006b) and higher water quality. Previous studies have shown that several fish species demonstrate a great ability to use such systems and a high plasticity when facing the triggering device (e.g. a metal rod protected or not in a PVC cylinder). Individual can push, pull, bite (Covès et al., 2006) or even use a dorsally attached external tag (Millot et al., 2014) to actuate the trigger which delivers food for the entire group. These devices allow the assessment of numerous variables such as apparent group feed demand and consumption (when uneaten food is counted); feeding activity and feeding rhythms in Arctic char Salvelinus alpinus, and European seabass, Dicentrarchus labrax (Boujard et al., 1996; Jobling et al., 2001; Rubio et al., 2004; Covès et al., 2006b); circadian rhythms in Rainbow trout Oncorhynchus mykiss (Alanärä, 1992b; a; Boujard and Leatherland, 1992; Alanärä, 1996; Chen et al., 2002), and feed preferences in seabass (Paspatis et al., 2002). Such device also allowed to evaluate the effects of fasting in seabass (Echevarria et al., 1997; Aranda et al., 2001; Benhaïm et al., 2012), Olive flounder Paralichthys olivaceus (Miyazaki et al., 2000) or Barramundi Lates calcarifer (Tian and Qin, 2003); and the effects of domestication and selection on behaviour in seabass (Millot et al., 2011). Self-feeder devices have been used recently in Atlantic cod Gadus morhua (Millot et al., 2012) and lead to the discovery of innovative behaviour (Millot et al., 2013). They were also used to assess the effects of dopaminergic system activation on feeding behaviour in seabass (Leal et al., 2013). When coupled with a computer and a PIT tag detection antenna, self-feeder devices enable the study of the individual behaviours of fish living in groups of seabass (Covès et al., 2006b), as well as the assessment of changes to social structure of the group (Di-Poï et al., 2008; Millot and Bégout, 2009). 
Indeed, most studies report the existence of a social structure built around the device and the food dispenser. For example, social hierarchies have been observed in salmonids, such as Rainbow trout, (Alanärä and Brännäs, 1996; Alanärä et al., 1998), or Arctic char, (Alanärä, 1993; Brannas and Alanara, 1993), with dominant fish taking position near the feeder and the dispenser. These authors identified three fish categories (dominants, sub-dominants and subordinates) and showed that social rank was directly correlated with self-feeding device triggering activity. Dominant fish had the highest actuation level, followed by sub-dominants and then subordinates, resulting in higher specific growth rates for dominant fish.

The European seabass is a high commercial value marine teleost and a model species of Mediterranean aquaculture. The average worldwide aquaculture production of this species since 2007 is estimated at 125,000 metric tons per year (Tveteras and Nystoyl, 2011). Numerous studies have shown that seabass can learn to actuate the trigger of a self-feeder apparatus (Anthouard et al., 1986; Sánchez-Vázquez et al., 1994; Boujard et al., 1996; Azzaydi et al., 1998; Covès et al., 1998; Sánchez-Vázquez et al., 1998; Rubio et al., 2004). However, no dominance-subordination relationships have been observed in this species (Covès et al., 2006b; Di-Poï et al., 2008; Millot et al., 2008; Millot and Bégout, 2009; Benhaïm et al., 2012). Following work done on salmonids, Covès et al. (2006) have kept the terminology 'social structure' based on triggering activity and Di Poi et al. (2007) proposed a producers-scroungers social organization instead of a hierarchical one. This term is hence linked to an individual specialization among the group: some high-triggering fish that could play the role of producers and zero or low-triggering fish playing the role of scroungers. This has been also observed in other animals such as insects and birds (Giraldeau and Beauchamp, 1999; Coolen et al., 2001). In seabass, three categories: High Triggering (HT), Low Triggering (LT) and Zero Triggering fish (ZT) have been defined and the proportions of these categories vary according to different studies. One or two individuals were responsible for $80 \%$ of triggering activity in a small population (50-100 individuals) over a 60 day period under a reward regime of 1 or 2 pellets per individual given at each actuation (Covès et al., 2006b), whereas two or three fish were responsible for about $45 \%$ under a 
reward of one pellet per individual (Millot et al., 2008). The rest of the population could be divided into two groups: LT fish were responsible for $19-26 \%$ of the triggering activity and ZT fish triggered less than $2 \%$ of total actuation events (Di-Poï et al., 2008).

Several studies have shown that seabass from different triggering categories do not differ in initial or mean growth rate, or in mean initial and final body weight (Covès et al., 2006b; Di-Poï et al., 2007; DiPoï et al., 2008; Benhaïm et al., 2012). In addition, fish from the different categories are not physiologically different (as measured by blood variables (Millot and Bégout, 2009; Benhaïm et al., 2012)); and Covès et al. (2006) and Benhaïm et al. (2012) reported that there is no difference in sex ratio between the categories. Therefore, in contrast with salmonids, there are no obvious explanations for this social structure in European seabass. Although Millot et al. (2008) showed a favourable growth window when fish were $\mathrm{HT}$, feeding motivation as triggered by a fasting period was not correlated with triggering activity (Benhaïm et al., 2012). However, Benhaïm et al. (2012) suggested that triggering activity is linked to personality traits and further perspectives could arise. On one hand this could provide a determinant of such triggering activity towards a causative explanation and on the other hand, as an applied perspective, this could enable manipulating population to favour the presence of more HT fish leading to better structured population achieving better growth.

The number of studies on personality traits and coping styles has increased in recent years, and these studies have provided some explanations for the adaptive value of individual variation in behaviour (Wilson et al., 1994; Koolhaas et al., 1999; Sih et al., 2004; Réale et al., 2007; Wolf et al., 2007; Dingemanse et al., 2010). Animal personality or coping style can be defined as a correlated set of individual behavioural and physiological characteristics that are consistent over time and across situations (Wilson et al., 1994; Koolhaas et al., 1999; Sih et al., 2004). It covers numerous traits, such as boldness and shyness (willingness to take risks), avoidance of novelty, exploration, activity, aggressiveness and sociability (Réale et al., 2007). One of the main aspects of personality is the 
boldness-shyness continuum. According to Coleman and Wilson (1998), individuals from a fish population can be categorized into three sub-groups based on their predisposition to take risks: bold, intermediate and shy. Usually, boldness is associated with a proactive strategy contrary to shyness that is associated with a reactive strategy. Bold fish take more risks and explore their environment faster (less cautiously) when exposed to novelty ( $\varnothing$ verli et al., 2006; MacKenzie et al., 2009). In contrast, shy individuals tend to be risk averse and are generally neophobic (Verbeek et al., 1994; Wilson et al., 1994), show a higher behavioural flexibility (Bolhuis et al., 2004) and are more responsive to their environment (Verbeek et al., 1994). Intermediate fish are in the middle of these two extremes.

There are standard methods for measuring boldness in fish (Brown et al., 2007), such as the latency to leave a safe area to explore a novel, less safe area (Budaev et al., 1999a; b; Fraser et al., 2001; Brown et al., 2007; Biro et al., 2010; Eriksson et al., 2010). Among numerous behavioural tests assessing boldness, the open field test (Budaev et al., 1999a; b; Yoshida et al., 2005) or the restraint test/confinement test (Silva et al., 2010; Castanheira et al., 2013) are widely used and were chosen. In this study, we aimed to explore the link between the social structure that builds around a selffeeder device and personality traits in European seabass. We characterised individual personality traits and assessed the links with individual triggering activity under group self-feeding conditions.

\section{Materials and methods}

\subsection{Fish and experimental conditions}

Fish were hatched and reared at the experimental research station of Ifremer (Palavas-les-Flots, France) according to seabass rearing standards (Chatain, 1994). A sample of 600 fish was transported at 86 days post hatching (dph) on 06/04/2012 to the Fish Ecophysiology Platform of La Rochelle (PEP, http://wwz.ifremer.fr/pep, France). After 8 days of acclimatisation, a sub-sample of 200 fish (0.86 \pm $0.28 \mathrm{~g}$ in mass (mean \pm standard deviation (SD)) was distributed (50 fish per tank) in four $400 \mathrm{~L}$ tanks (T1 to T4) located in a dedicated room. At $257 \mathrm{dph}$, the fish, now weighing $15.26 \pm 5.00 \mathrm{~g}$, were 
tagged with $12 \mathrm{~mm}$ conventional PIT tag to monitor each fish individually using a self-feeder equipped with PIT tag detection antenna. The four $400 \mathrm{~L}$ tanks were supplied with sand filtered seawater in a recirculated system (flow rate of $4 \mathrm{~m}^{3} \mathrm{~h}^{-1}$ in each tank, and $15 \%$ water renewal per day).Tanks were surrounded by an opaque black curtain to avoid any disturbance to the fish. A white light (Philips, 80W) was suspended above each tank. The light cycle was controlled (14 hours day/ 10 hours night) throughout the experiment. The physico-chemical properties of the water were monitored daily to guarantee optimum conditions. Water temperature was maintained at $20.6 \pm 0.3$ ${ }^{\circ} \mathrm{C}, \mathrm{O}_{2}$ saturation at $75.4 \pm 8.9 \%$ and salinity at $26.9 \pm 0.9 \mathrm{~g} \mathrm{~L}^{-1}$. Ammonia, nitrite and nitrate concentrations were lower than $0.05 \pm 0.05,0.13 \pm 0.06$ and $0.97 \pm 0.11 \mathrm{mg} \mathrm{L}^{-1}$, respectively.

Fish were hand fed with commercial food (first with INICIOplus (BIOMAR ${ }^{\circledR}$, France) of increasing pellets size when fish were between $0.86-15 \mathrm{~g}$ then with Neo Start $3 \mathrm{~mm}$, Le Gouessant aquaculture, France) until the self-feeder devices were installed at $268 \mathrm{dph}$ and delivered the same food (Neo Start, $3 \mathrm{~mm})$.

\subsection{Food demand behaviour and self-feeder apparatus}

The device to operate the feeder comprised a screened type sensor (a metal rod protected in a PVC cylinder surrounded by the tag detection antenna, Covès et al. (2006)), and a control box linked to a computer. After each actuation, fish were rewarded with pellets (at least one per fish) and feed dispensers were regulated to distribute always the same quantity of food, which corresponded to a mean of $1.75 \pm 0.19 \mathrm{~g}$. The reward level was a compromise between minimizing wastage, and optimizing feed allocation to the group. Such a set up allowed us to monitor two variables of interest on a daily basis: the individual feed demand behaviour and the apparent feed consumption of the group (i.e. one group per tank). The apparent feed consumption of the group was calculated from the food quantity dispensed minus the waste collected in the sediment trap and counted. Triggering activity recordings were done continuously except before and during fish biometry sessions (triggers were inactivated and there were no recordings for $48 \mathrm{~h}$ at each biometry session). 
170

171

172

173

174

175

176

177

178

179

180

181

182

184

185

186

187

188

189

190

191

192

193

194

Feed demand behaviour was followed over 131 days from $268 \mathrm{dph}$ to $399 \mathrm{dph}$. This duration was chosen to be more than double the duration of the period that an individual held high-triggering status ( $63 \pm 16$ days on average) as demonstrated by Millot and Bégout (2009) in order to observe a clear status acquisition in $\mathrm{HT}$ fish. For each day, the triggering activity was recorded and the quantity of food distributed in each tank calculated.

\subsection{Evaluation of biological performances}

The growth of all fish was followed from $257 \mathrm{dph}$ to $391 \mathrm{dph}$. Biometric measurements were performed at $257 \mathrm{dph}$, at $303 \mathrm{dph}$, at $335 \mathrm{dph}$, at $369 \mathrm{dph}$, at $391 \mathrm{dph}$ at $430 \mathrm{dph}$. We performed a last biometry at $430 \mathrm{dph}$ in order to gather the individual body length information to convert "total distance travelled" in the open field test to body -length (BL). This last biometry was not taken into account for analyses of growth (body mass and SGR) since behavioural tests could impact fish growth. The variables chosen to evaluate biological performances within periods (i.e. in between biometric measurements) were the following: body mass (BM, g) and specific growth rate (SGR (\% of mass per day $)=100\left(\operatorname{Ln~BM}_{f^{-}} \operatorname{Ln} B M_{i}\right) / t$, where $B_{\mathrm{f}^{\prime}}$ and $B M_{i}$ are the initial and final body mass $(g)$, respectively and $t$ is the number of total days). SGR were compared according to triggering category only in fish of interest selected for behavioural tests and during the food demand monitoring (from $257 \mathrm{dph}$ to $391 \mathrm{dph}$; i.e. five biometric measurements). At the end of experiment, all the fish were killed and their sex determined following Ferrari et al. (2014).

\subsection{Characterization of triggering categories}

Fish were characterized according to their triggering activity. They were classified into three categories by calculating each individual's contribution each day to the total number of trigger actuations within the tank (\%) and then we averaged daily contribution across the whole duration of the experiment (131 days). As reviewed in Benhaïm et al, (2012), the percentage of triggering for each category (HT/LT/ZT) is extremely variable according to authors but the proportion of fish in each 
category remains the same. As the most important is to categorize fish according to consistency of the triggering activity, here we chose: High-triggering HT ( $\geq 8 \%$ of total actuations), Low-triggering LT $(<8 \%)$, and Zero-triggering ZT (<2\%).

\subsection{Characterization of personality traits}

Once each individual was attributed a triggering category, we could determine the number of HT fish, take randomly the same number of fish belonging to $\mathrm{LT}$ or $\mathrm{ZT}$ and characterize them using a restraint and an open field with a shelter tests to assess individual boldness and exploration. Both tests were carried out on the same individuals.

\subsubsection{Restraint test}

A restraint test was performed at $423 \mathrm{dph}$. For each tank, all fish were caught, identified and selected fish isolated in buckets. Just before running the test, they were gently placed by hand in an emerged net (Europet Bernina ${ }^{\circledR}, 15 \mathrm{~cm}$ ) fixed on a holder for 3 min (adapted from Silva et al., 2010; Martins et al., 2011; Castanheira et al., 2013) and their behaviour was video recorded (Ethovision XT recording, Noldus, The Netherlands; camera Ikegami CD48E ; 2.8 - 12 mm Computar ${ }^{\circledR}$ lens). After the tests, all individuals were placed back in their respective tanks. Individual behaviour was analyzed with the "manual scoring" module of Ethovision XT. Individual variables of interest were calculated for the whole duration of the 3 min test and were "latency before first escape attempt (s)", "total escape duration (s)" and "number of escape attempts". An escape attempt was defined as an elevation of the body in the net.

\subsubsection{Open field test}

An open field test (OFT) was performed at $433 \mathrm{dph}$. For each tank, all fish were caught, identified and selected fish placed together in a smaller tank before being challenged. The open field $(72 * 72 \mathrm{~cm}$ with a water height of $18 \mathrm{~cm}$ ) was divided into two virtual zones (border and centre, Figure 2) and a shelter (opaque PVC box $18 * 18 * 18 \mathrm{~cm}$ closed by a vertically sliding trapdoor) was placed in one 
corner of the open field. The centre zone was considered as a risky area since thigmotaxis (staying close to the walls of an arena) is a common measure indicating increased shyness in this test (Maximino et al., 2010; Dahlbom et al., 2011). The whole setup was placed on an infrared floor (IR floor $1 \times 1 \mathrm{~m}$, Noldus, The Netherlands) to prevent the reflection of light. The whole experiment was video recorded at 25 frames per second (Ethovision XT recording, Noldus, the Netherlands; camera Ikegami CD48E; 2.8-12 mm Computar ${ }^{\circledR}$ lens equipped with an IR filter). Selected fish were individually placed in the shelter. After a $5 \mathrm{~min}$ acclimatization period, the door was gently opened. If the individuals did not go out of the shelter within 20 minutes following the acclimatization time, the experiment was stopped and a latency of 1200 seconds was attributed. If the fish went out of the shelter, it was allowed to explore the open field for 20 minutes. Variables of interest were extracted over the whole 20 min period with Ethovision XT and were as follows: individual "latency to emerge from the shelter (s)", "in shelter duration (s)", "time spent in centre zone (s)", "time spent in border zone $(\mathrm{s})$ ", "total distance travelled (body length, $\mathrm{BL})$ ", "mean distance from the shelter $(\mathrm{cm})$ "and "number of returns to the shelter". For each individual, distance travelled was divided by fish body length $(\mathrm{BL}$ in $\mathrm{cm}$ ) to standardize values and avoid bias due to variation in fish size.

\subsection{Data analysis}

After verification of distribution normality and homoscedasticity (Dagnélie, 1975), individual body mass of all fish were compared between tanks at the beginning ( $257 \mathrm{dph})$ and at the end of the feeding follow-up (391 dph) by one way ANOVA with Tank as a fixed factor.

For personality tests, the sample size was determined by the number of HT fish ( $\mathrm{N}=10 \mathrm{HT}$ in total when all 4 tanks were pooled) and the same number of $L T+Z T$ fish was selected ( $N=10, L T+Z T$ because it was not possible to test more than 20 individuals in the same day). Body mass of selected fish ( $N=20$ in total) were compared using a Mann-Whitney (MW) test. The SGR of these selected individuals were compared by Repeated-Measure ANOVA with triggering category (HT versus LT+ZT) as a between-subjects factor and date (four dates) as a within-subjects factor. Body mass and SGR 
are given as mean \pm SD unless otherwise stated. Average food demand per tank was analysed by ANOVA with Tank as a fixed factor. The proportion of individuals and sex ratio per triggering category between tanks was analysed by a Chi square test. All variables of interest from both tests were compared between the triggering categories (HT versus LT $+\mathrm{ZT}$ ) using a Mann-Whitney.

The links between individual triggering activity ("individual percentage of actuation") and individual responses observed in the variables from the restraint and open field tests were assessed by non parametric Spearman's correlation on rank order due to small sample sizes. This strategy was chosen to take advantage of the continuous nature of all the variables and because using correlation to assess personality traits is actually a usual method (Martins et al, 2011, 2012; Herde \& Eccard, 2013; Magnhagen et al, 2004; Castanheira et al, 2013a, b). For the open field test, fish that did not go out of the shelter were removed from analyses, except for the variable latency to emerge from the shelter. All analyses were performed with Statistica7 (Statsoft) with a threshold for significance of $p<0.05$.

\section{Results}

\subsection{Growth, sex ratio and social structure around the self-feeder}

Eight fish belonging to LT+ZT category died over the experiment duration, representing $4 \%$ of the population. Body mass at the beginning of the experiment was $15.50 \pm 4.99 \mathrm{~g}(257 \mathrm{dph})$ and $47.54 \pm 15.22 \mathrm{~g}$ at the end ( $391 \mathrm{dph}$ ). There were no differences in initial body mass between tanks ( $\mathrm{F}$ $(3,203)=1.8, p=0.144)$. However, there was a difference in final body mass $\left(F_{(3,198)}=5.6, p<0.001\right)$ and Tukey HSD post hoc test showed that body mass was significantly lower in T4 (36.12 $\pm 11.78 \mathrm{~g})$ than in T1 (51.41 $\pm 14.03 \mathrm{~g})$ and T2 $(50.73 \pm 16.34 \mathrm{~g})(\mathrm{p}<0.001$ and $\mathrm{p}<0.05$, respectively), but not different than T3 $(45.92 \pm 14.37 \mathrm{~g})$.

Triggering categories showed differences in initial body mass $(24.49 \pm 9.13 \mathrm{~g}$ for HT and $17.38 \pm 4.08$

$\mathrm{g}$ for $\mathrm{LT}+\mathrm{ZT}$ ) and this was true all along the experiment duration (RM-ANOVA, $F_{(1,18)}=4.73, p=0.04$ ). 
However, no differences were observed on SGR all along the experiment duration (during the first period SGR was $0.81 \pm 0.26$ for $\mathrm{HT}(\mathrm{N}=10)$ and $0.79 \pm 0.23$ for $\mathrm{LT}+\mathrm{ZT}$ fish $(\mathrm{N}=10)$; during the last period SGR was $0.78 \pm 0.20$ for $\mathrm{HT}$ fish and $0.83 \pm 0.20$ for LT+ZT fish (RM-ANOVA, $\left.\left.F_{(1,18)}=0.36, p=0.56\right)\right)$. Average food demand over the whole feeding follow-up period (131 days) for tank one, two, three and four were $0.80 \pm 1.10 ; 1.19 \pm 1.60 ; 1.23 \pm 1.38$ and $0.97 \pm 1.29$ g.kg , respectively. Food demand was different between tanks (ANOVA, $\left.F_{(3,3348)}=17.6 ; p<0.001\right)$, and tanks 1 and 4 had significantly lower food demand than tanks 2 and 3 (Tukey HSD Post-hoc, $p<0.001$ ). We observed no food wastage in any tank and we observed a similar rhythm in feeding activity in all tanks, with a peak between 08:00am - 10:00am and between 19: 00pm-22: 00pm. Sex ratios were similar between tanks ( $68.7 \pm 12.9 \%$ of males). Social structure was as follows: most fish were ZT (72.7\% in $\mathrm{T} 1,74.0 \%$ in $\mathrm{T} 2,66.7 \%$ in $\mathrm{T} 3$ and $78.0 \%$ in $\mathrm{T} 4$ ); $\mathrm{LT}$ fish represented $21.8 \%$ in $\mathrm{T} 1,22.2 \%$ in $\mathrm{T} 2$, $27.4 \%$ in $\mathrm{T} 3$ and $16.0 \%$ in $\mathrm{T} 4$; and $\mathrm{HT}$ fish accounted for $5.4 \%$ in $\mathrm{T} 1,3.7 \%$ in $\mathrm{T} 2,5.9 \%$ in $\mathrm{T} 3$ and $6.0 \%$ in T4 (no significant difference between tanks: $\mathrm{Chi}^{2}=2.319, \mathrm{p}=0.88$ ). On average over all tanks, $\mathrm{ZT}, \mathrm{LT}$ and HT categories represented respectively $72.9 \pm 4.7 \% ; 21.9 \pm 4.7$ and $5.2 \pm 1.1 \%$ of individuals in tanks. According to the tank, there were two or three HT fish responsible for about $45 \%$ of the total number of actuation. Over the whole experiment duration, the mean percentage of actuation was $15 \%$ (range 8-35) for HT fish, 4\% (range 3-7) for LT fish and $0.6 \%$ (range 0-2) for ZT fish. Sex ratio was not different between triggering categories $\left(\mathrm{Chi}^{2}=1.37, \mathrm{p}>0.05\right)$.

\subsection{Responses to personality tests}

All variables from both tests (Restraint and OFT) and corresponding values (mean $\pm \mathrm{SD}$; range (minmax)) are presented in Table 1. This table shows the pronounced inter individual variability in all behavioural variables tested. In the restraint test, $\mathrm{HT}$ fish tend to escape less from the net than LT $+\mathrm{ZT}$ fish (Table 1), but this was not statistically different $(\mathrm{MW}, \mathrm{Z}=0.14 \mathrm{p}=0.89$ ) due to the pronounced inter individual variation. Same results were observed for total escape duration (Table 1; MW, Z=- 
$0.05, p=0.96)$. However, $H T$ fish tended to have higher latency before first escape attempt than $L T+Z T$ (Table 1) but this was again not significant ( $M W, Z=-0.27, p=0.79$ ). In the OFT, HT fish tended to have higher latency to emerge from the shelter than LT+ZT fish (Table 1), but this was not statistically different (MW, $Z=-1.63, p=0.10)$. The time spent in shelter tended to be higher for $\mathrm{HT}$ fish (Table 1 ) but was not statistically different ( $M W, Z=-1.81, p=0.07$ ). HT fish tended also to spent less time in central and border area than LZ $+\mathrm{ZT}$ fish (Table 1), but this was still not statistically different (MW, $Z=1.08, p=0.28$ and $Z=1.18, p=0.24$ ). $H T$ fish tended to be less active (Distances travelled) than $L T+Z T$ fish (Table 1), but this was not statistically different (MW, $Z=1.18, p=0.24)$. Finally, $H T$ fish tended to stay closer to the shelter than LT + ZT fish (Table 1 ) but Kruskall Wallis test did not shown any differences (MW, $Z=1.45, p=0.15)$.

A correlation analysis between each variable from both tests is shown in table 2 . The "latency before first escape attempt" in the restraint test was positively correlated with "latency to emerge from the shelter" in the OFT ( $r_{s}=0.63, p<0.01 ;$ Figure 2). The "number of escape attempt" in the restraint test was negatively correlated with "time spent in shelter" during the open field test $\left(r_{s}=-0.48, p=0.04\right.$; Table 2). We also verified the absence of order effect in the OFT (correlation between latency to leave the safe area and order of passage: $r_{s}=0.03, p=0.89$ ) and size matching between fish characterised in behavioural test from each triggering category ( $M W, Z=0.53, p=0.53$ ).

\subsection{Links between individual triggering activity and personality tests variables}

\subsubsection{Restraint test}

We found that "latency before first escape attempt" and the "number of escape attempts" were significantly negatively correlated (values are given in Table 1 and 2). The variable "total escape duration" was significantly positively correlated with "number of escape attempts") and negatively correlated with "latency before first escape attempt"). However, the variables "latency before first escape attempt", "total escape duration" and "number of escape attempts" were not correlated with individual actuation percentage (Table2). 
Only two individuals did not move out of the shelter and were removed from downstream analyses. They were HT fish. The variable "latency to emerge from the shelter" was not correlated with any other variable of interest (Table 2). The variable "in shelter duration" was negatively correlated with "time spent in center zone", "time spent in border zone", "total distance traveled" and "mean distance from the shelter" but positively correlated with "in shelter duration" (Table 2). The variable "time spent in center zone" was positively correlated with "time spent in border", "total distance travelled" and "mean distance from the shelter", but not with "number of returns to the shelter" (Table 2). The variable "time spent in border" was negatively correlated with "mean distance from the shelter" and "number of returns to the shelter" but not with "total distance travelled" (Table 2). The variable "total distance travelled" was positively correlated with "mean distance from the shelter" but was not correlated with "number of returns in the shelter" (Table 2). Finally, "mean distance from the shelter" was negatively correlated with "number of returns to the shelter".

We found a positive correlation between "individual actuation percentage" and "latency to emerge from the shelter" $\left(r_{s}=0.53 ; p=0.02\right.$; Figure $\left.3 A\right)$ and "in shelter duration" $\left(r_{s}=0.54 ; p=0.02\right.$; Figure 3B). In addition, the "individual actuation percentage" was negatively correlated with the "mean distance from the shelter" $\left(r_{s}=-0.55 ; p=0.02\right.$; Figure $\left.3 C\right)$ and "time spent in centre zone" $\left(r_{s}=-0.52 ; p=0.03\right.$; Figure 3D). The "individual actuation percentage" was positively correlated with "number of returns to the shelter" $\left(r_{s}=0.40, p=0.03\right)$. We found no significant correlations for any other variables (Table 2).

\section{Discussion}

The aim of this study was to investigate further seabass social structure that builds around the selffeeding system and to determine if this structure may be partly linked to personality traits. We determined social structure from each individual's contribution to total food demand. We then 
342

343

344

345

346

347

348

349

350

351

352

assessed personality (i.e. boldness-shyness axis) by common behavioural tests in individual fish from $H T$ and $L T+Z T$ groups.

The self-feeding experiment confirmed the social structure observed in previous studies (Di-Poï et al., 2007; Millot et al., 2008; Millot and Bégout, 2009; Benhaïm et al., 2012), with three well represented categories of fish. Our findings confirm that in a group of 50 seabass, only $5 \%$ of the individuals are responsible for the majority of food request. The rest of the population could be divided into two groups, with LT fish making up almost $22 \%$ and ZT fish constituting $73 \%$. In accordance with previous studies on seabass (Benhaïm et al., 2012) and other species such as bird, Spice finches (Lonchura punctulata, Coolen et al., 2001), we found that neither SGR nor sex differences could explain this structure. In addition, aggression tests were performed on seabass at a similar age and did not show any aggressive interactions between conspecifics (Ferrari et al, submitted).We found however, that HT fish had higher mean body mass at the beginning and all along the experiment duration. This link between initial body mass and triggering activity is however highly variable. Indeed, (Covès et al., 2006a) did not find any differences in initial and final body mass according to the triggering categories while Ferrari et al, (in preparation) found that HT fish were lighter than other categories. The fact that no SGR differences were observed between triggering categories means that fish did not take advantage from their triggering status, which is consistent throughout the literature (Covès et al., 2006a; Millot and Bégout, 2009; Benhaïm et al., 2012).

In the present study, we observed personality differences between high triggering and low or zero triggering individuals in the open field test. Latency to emerge from a shelter showed high interindividual variability and was still significantly positively correlated with individual actuation percentage. Fish that emerged quickly from the shelter (i.e. bold fish) performed few trigger actuations and conversely. In addition, HT fish spent significantly more time close to the shelter than $\mathrm{LT}+\mathrm{ZT}$ fish, confirming the bolder character of $\mathrm{LT}+\mathrm{ZT}$ fish (or conversely the shyer character of $\mathrm{HT}$ fish). Moreover, HT fish spent less time in the center zone (which is a risky zone), returned significantly more to the shelter and were less explorative than LT+ZT fish. All together, these results 
demonstrate that HT fish are shyer than LT+ZT fish. In addition, the consistency of all the different traits in HT and LT+ZT fish matches with the definition of personality. According to numerous studies (Budaev et al., 1999a; b; Fraser et al., 2001; Brown et al., 2007; Biro et al., 2010; Eriksson et al., 2010), the time to emerge from a shelter gives an indication of the individual's boldness, and swimming behaviour in the open field gives an indication of boldness, activity and exploration (Millot et al., 2009a). This test has been successfully used in mammals (mainly in rodents), but also in fish: in Guppy, Poecilia reticulata (Budaev1997b), Convict cichlid Steatocranus casuarius (Budaev et al. 1999b), and Rainbow trout (Sneddon, 2003).

The restraint test did not reveal any behavioural differences between triggering categories. However, although this test has been used successfully to sort fish according to their coping strategies (Silva et al., 2010; Castanheira et al., 2013), it is highly invasive and stressful and is far removed from a natural situation, contrary to the OFT. The positive correlation between the latency before the first attempt to escape from the net and the latency to emerge from the shelter but also the negative correlation between the number of escape attempts and the time spent in shelter show that distinct personality exist in European sea bass: individual with a passive response during the restraint test tended to be shyer during the open field test. Such analysis across test should be further developed and could be indicative of a behavioural syndrome in sea bass. Additionally, because sea bass are known to be gregarious species and some studies have shown that testing personality of social species using individual based test may influence behavioural responses (reviewed by (Ashley, 2007)), it would be interesting to couple triggering activity (which occur in group situation) and another personality test done in group such as the risk taking (Millot et al., 2009b) or the hypoxia tests (Laursen et al., 2011). This endeavour could improve data interpretation since here significant correlations explained only half of the variability of our dataset: as a group HT fish characteristic were demonstrably not independent of results returned by the open field test but the nature of our individual based test may have increased inter-individual variability. 
Self-feeders are tools to study individual behaviour in group and undisturbed conditions. When fish are placed under self-feeding conditions, they have to find their own food source (by the use of the self-feeder): the fish must find the trigger and learn how to activate and use it. This demonstrates an innovative foraging activity because they have never been in contact with such system before (Millot et al., 2013). In our study, the social foraging structure that builds around the self-feeder may be linked to the innovative ability of some fish, which in turn is linked to behavioural syndromes. Bold individuals are usually recognized as better competitors, with higher feed intake (Øverli et al., 1998), higher growth rates (Huntingford, 2004; Huntingford and Adams, 2005) than shy individuals. These individuals are also more dominant and take more risks to meet the demand of their faster pace of life (Biro and Stamps, 2008; Réale et al., 2010). The high innovative abilities of poor competitors (who are usually reactive) have been already reported in a previous study (Cole and Quinn, 2012). Interestingly, when a fish entered the PVC cylinder containing the trigger, we observed a subgroup of 4 or 5 fish shoaling close behind, oriented towards the HT fish whereas other fish were waiting just under the food dispenser (as described in Di Poï et al., 2008). We hypothesize that LT+ZT fish have priority access to food resources under the feeder, which forces shy fish (HT) to find another strategy to feed themselves and compensate (i.e. activate the feeder until they can eat at will). This would force the HT fish to adopt a "producers" strategy. Indeed, schooling fish forage according to the "scroungers/producers" theory. Group foragers commonly feed from food discovered, captured or otherwise made available by companions (Coolen et al., 2001). This so-called 'joining' is reported in people, other primates, social carnivores, birds, fish, spiders and insects (Giraldeau and Beauchamp, 1999). When all individuals in a group look for food, and every time a food source is discovered, all other animals in the group join the discoverer to share the food (Clark and Mangel, 1984). This seems to be the situation in the social structure we observe around the self-feeder, with only a few fish triggering the device and feeding the entire group. As reported in Di Poi et al., (2008), the hightriggering fish may play the role of the producer that feeds the entire group, whereas all other fish are opportunist individuals. This behaviour may also be linked to coping style. Proactive seabass may 
know where the food falls and thus be the first to eat but pay less attention to their environment. HT seabass (i.e. reactive fish) however, seem to be aware of the mechanism enabling the food delivery because they are more cautious when exploring their environment as already observed in birds (Verbeek et al., 1994). In accordance with Bolhuis et al. (2004) and Coppens et al. (2010), bold fish tend to develop behavioural routines (waiting under the pellet release area in our case), as opposed to shy ones which are more attentive about their environment, which may explain why they learn how to activate the feeder.

In conclusion, this experiment provides for the first time evidence that high triggering status in seabass is linked with personality traits (i.e. shyness) hence partly explaining the social structure that builds around a self-feeder device. This could be linked to a foraging strategy and this knowledge could be used to manipulate population composition to favour the presence of more HT fish leading to better structured population achieving better growth. In addition, this would be also an additional characteristic of personality traits of potential interest for selection programs aiming at improving growth since it is likely that bold or shy fish will flourish better depending on the environment characteristics. Further research is however needed first to fully understand the acquisition of triggering status and what are the causative factors and, second, to confirm the producer role hypothesis.

\section{Acknowledgments}

We are grateful to Marie-Odile Vidal from Ifremer experimental aquaculture station in Palavas-lesFlots who hatched the seabass for this study and to Didier Leguay from PEP in La Rochelle for the technical development of the open field apparatus. This study was conducted under the approval of the Animal Care Committee of France under the official license of M.L. Bégout (17-010). The research leading to these results has received funding from the European Union Seventh Framework 


\section{References}

Alanärä, A., 1992a. Demand-feeding as a self-regulating feeding system for rainbow trout in net-

Alanärä, A., 1992b. The effect of time-restricted demand feeding on feeding activity growth and feed conversion in rainbow trout (Oncorhynchus mykiss). Aquaculture 108, 357-368.

Alanärä, A., 1993. Significance of substrate and the timing of start-feeding in alevins of Arctic charr (Salvelinus alpinus). Aquaculture 111, 47-55.

Alanärä, A., 1996. The use of self-feeders in rainbow trout (Oncorhynchus mykiss) production. Aquaculture 145, 1-20.

Alanärä, A., Brännäs, E., 1996. Dominance in demand-feeding behaviour in Arctic charr and rainbow trout: the effect of stocking density. Journal of Fish Biology 48, 242-254.

Alanärä, A., Winberg, S., Brännäs, E., Kiessling, A., Höglund, E., Elofsson, U., 1998. Feeding behaviour, brain serotonergic activity levels, and energy reserves of Arctic char (Salvelinus alpinus) within a dominance hierarchy. Canadian Journal of Zoology 76, 212-220.

Anthouard, M., Desportes, C., Kentouri, M., Divanach, P., Paris, J., 1986. Etude des modèles comportementaux manifestés au levier par Dicentrarchus labrax, Diplodus sargus, Puntazzo puntazzo, Sparus aurata, et Lithognatus mormyrus (Poissons téléostéens), placés dans une situation de nourrissage auto-contrôlé. Biology of the Behavior 11, 97-110.

Aranda, A., Sánchez-Vázquez, F.J., Madrid, J.A., 2001. Effect of short-term fasting on macronutrient self-selection in sea bass. Physiology \& behavior 73, 105-109.

Ashley, P.J., 2007. Fish welfare: Current issues in aquaculture. Applied Animal Behaviour Science 104, 199-235.

Azzaydi, M., Madrid, J.A., Sánchez-Vázquez, F.J., Martínez, F.J., 1998. Effect of feeding strategies (automatic, ad libitum demand feeding and time-restricted demand-feeding) on feeding rhythms and growth in European sea bass (Dicentrarchus labrax L.). Aquaculture 163, 285-296.

Benhaïm, D., Bégout, M.-L., Péan, S., Brisset, B., Leguay, D., Chatain, B., 2012. Effect of fasting on selffeeding activity in juvenile sea bass (Dicentrarchus labrax). Applied Animal Behaviour Science 136, 63-73.

Biro, P.A., Beckmann, C., Stamps, J.A., 2010. Small within-day increases in temperature affects boldness and alters personality in coral reef fish. Proceedings of the Royal Society B: Biological Sciences 277, 71-77.

Biro, P.A., Stamps, J.A., 2008. Are animal personality traits linked to life-history productivity? Trends in Ecology \& Evolution 23, 361-368.

Bolhuis, J.E., Schouten, W.G.P., Leeuw, J.A.d., Schrama, J.W., Wiegant, V.M., 2004. Individual coping characteristics, rearing conditions and behavioural flexibility in pigs. Behavioural Brain Research 152, 351-360.

Boujard, T., Jourdan, M., Kentouri, M., Divanach, P., 1996. Diel feeding activity and the effect of timerestricted self-feeding on growth and feed conversion in European sea bass. Aquaculture 139, 117127.

Boujard, T., Leatherland, J.F., 1992. Demand-feeding behavior and diel pattern of feeding activity in Oncorhynchus mykiss held under different photoperiod regimes. Journal of Fish Biology 40, 535-544.

Brannas, E., Alanara, A., 1993. Monitoring the demand feeding activity of individual fish with a demand feeding system. Journal of Fish Biology 42, 209-215. 
Brown, C., Burgess, F., Braithwaite, V., 2007. Heritable and experiential effects on boldness in a tropical poeciliid. Behavioral Ecology and Sociobiology 62, 237-243.

Budaev, S.V., Zworykin, D.D., Mochek, A.D., 1999a. Consistency of individual differences in behaviour of the lion-headed cichlid, Steatocranus casuarius. Behavioural Processes 48, 49-55. behaviour profile in the convict cichlid: a correlation study. Animal Behaviour 58, 195-202.

Castanheira, M.F., Herrera, M., Costas, B., Conceição, L.E.C., Martins, C.I.M., 2013. Can We Predict Personality in Fish? Searching for Consistency over Time and across Contexts. PLoS ONE 8, e62037.

Chatain, B., 1994. Estimation et amélioration des performances zootechniques de l'élevage larvaire de Dicentrarchus labrax et de Sparus auratus.

Chen, W.M., Mayumi, N., Mitsuo, T., 2002. Circadian rhythms and individual variability of self-feeding activity in groups of rainbow trout Oncorhynchus mykiss (Walbaum). Aquaculture Research 33, 491500.

Clark, C.W., Mangel, M., 1984. Foraging and flocking strategies:information in an uncertain environment. American Naturalist 123, 626-641.

Cole, E.F., Quinn, J.L., 2012. Personality and problem-solving performance explain competitive ability in the wild. Proceedings of the Royal Society B: Biological Sciences 279, 1168-1175.

Coleman, K., Wilson, D.S., 1998. Shyness and boldness in pumpkinseed sunfish: individual differences are context-specific. Animal Behaviour 56, 927-936.

Coolen, I., Giraldeau, L.-A., Lavoie, M., 2001. Head position as an indicator of producer and scrounger tactics in a ground-feeding bird. Animal Behaviour 61, 895-903.

Covès, D., Beauchaud, M., Attia, J., Dutto, G., Bouchut, C., Bégout Anras, M.L., 2006a. Long-term monitoring of individual fish triggering activity on a self-feeding system: An example using European sea bass (Dicentrarchus labrax). Aquaculture 385, 385-392.

Covès, D., Beauchaud, M., Attia, J., Dutto, G., Bouchut, C., Bégout, M.L., 2006b. Long-term monitoring of individual fish triggering activity on a self-feeding system: An example using European sea bass (Dicentrarchus labrax). Aquaculture 253, 385-392.

Covès, D., Gasset, E., Lemarié, G., Dutto, G., 1998. A simple way of avoiding feed wastage in European sea bass, Dicentrarchus labrax, under self-feeding conditions. Aquat. Living Resour. 6, 395401.

Dagnélie, P. (Ed.), 1975. Théorie et méthodes statistiques. Applications agronomiques.

Dahlbom, S.J., Lagman, D., Lundstedt-Enkel, K., Sundström, L.F., Winberg, S., 2011. Boldness Predicts Social Status in Zebrafish (<italic>Danio rerio</italic>). PLoS ONE 6, e23565.

Di-Poï, C., Attia, J., Bouchut, C., Dutto, G., Covès, D., Beauchaud, M., 2007. Behavioral and neurophysiological responses of European sea bass groups reared under food constraint. Physiology \& behavior 90, 559-566.

Di-Poï, C., Beauchaud, M., Bouchut, C., Dutto, G., Covès, D., Attia, J., 2008. Effects of high food demand fish removal in groups of juvenile sea bass (Dicentrarchus labrax). Canadian Journal of Zoology 86, 1015-1023.

Dingemanse, N.J., Kazem, A.J.N., Réale, D., Wright, J., 2010. Behavioural reaction norms: animal personality meets individual plasticity. Trends in Ecology \& Evolution 25, 81-89.

Echevarria, G., Martinez-Bebia, M., Zamora, S., 1997. Evolution of Biometric Indices and Plasma Metabolites During Prolonged Starvation in European Sea Bass (Dicentrarchus labrax, L.). Comparative Biochemistry and Physiology 118A, 111-123.

Eriksson, C.A., Booth, D.J., Biro, P.A., 2010. 'Personality' in two species of temperate damselfish. Marine Ecology Progress Series 420, 273-276.

Fraser, D., Gilliam, J., JDaley, M., NLe, A., Skalski, G., 2001. Explaining Leptokurtic Movement Distributions: Intrapopulation Variation in Boldness and Exploration. The American Naturalist 158, 124-135.

Giraldeau, L.A., Beauchamp, G., 1999. Food exploitation: searching for the optimal joining policy. Trends in Ecology \& Evolution 14, 102-106. 
Huntingford, F.A., 2004. Implications of domestication and rearing conditions for the behaviour of cultivated fish. Journal of Fish Biology 65, 122-142.

Huntingford, F.A., Adams, C., 2005. Behavioural syndromes in farmed fish: implications for production and welfare. Behaviour 142, 1207-1221.

Jobling, M., Covès, D., Damsgard, B., Kristiansen, H.R., Koskela, J., Petursdottir, E., Kadri, S., Gudmundson, O., 2001. Techniques for Measuring Feed Intake, in: Houliham, D., Boujard, T., Jobling, M. (Eds.), Food Intake in Fish, Blackwell Science, London, pp. 49-87.

Koolhaas, J.M., Korte, S.M., De Boer, S.F., Van Der Vegt, B.J., Van Reenen, C.G., Hopster, H., De Jong, I.C., Ruis, M.A.W., Blokhuis, H.J., 1999. Coping styles in animals: current status in behavior and stressphysiology. Neuroscience \& Biobehavioral Reviews 23, 925-935.

Laursen, D.C., L. Olsén, H., Ruiz-Gomez, M.d.L., Winberg, S., Höglund, E., 2011. Behavioural responses to hypoxia provide a non-invasive method for distinguishing between stress coping styles in fish. Applied Animal Behaviour Science 132, 211-216.

Leal, E., Fernández-Durán, B., Agulleiro, M.J., Conde-Siera, M., Míguez, J.M., Cerdá-Reverter, J.M., 2013. Effects of dopaminergic system activation on feeding behavior and growth performance of the sea bass (Dicentrarchus labrax): A self-feeding approach. Hormones and Behavior 64, 113-121.

MacKenzie, S., Ribas, L., Pilarczyk, M., Capdevila, D.M., Kadri, S., Huntingford, F.A., 2009. Screening for Coping Style Increases the Power of Gene Expression Studies. PLoS ONE 4, e5314.

Maximino, C., de Brito, T.M., da Silva Batista, A.W., Herculano, A.M., Morato, S., Gouveia Jr, A., 2010. Measuring anxiety in zebrafish: A critical review. Behavioural Brain Research 214, 157-171.

Millot, S., Bégout, M.-L., 2009. Individual fish rhythm directs group feeding: a case study with sea bass juveniles (Dicentrarchus labrax) under self-demand feeding conditions. Aquatic Living Resources 22, 363-370.

Millot, S., Bégout, M.-L., Chatain, B., 2009a. Exploration behaviour and flight response toward a stimulus in three sea bass strains (Dicentrarchus labrax L.). Applied Animal Behaviour Science 119, 108-114.

Millot, S., Bégout, M.-L., Person-Le Ruyet, J., Breuil, G., Di-Poï, C., Fievet, J., Pineau, P., Roué, M., Sévère, A., 2008. Feed demand behavior in sea bass juveniles: effects on individual specific growth rate variation and health (inter-individual and intergroup variation). Aquaculture 274, 87-95.

Millot, S., Bégout, M.L., Chatain, B., 2009b. Risk-taking behaviour variation over time in sea bass Dicentrarchus labrax: effects of day-night alternation, fish phenotypic characteristics and selection for growth. Journal of Fish Biology 75, 1733-1749.

Millot, S., Nilsson, J., Fosseidengen, J., Bégout, M.-L., Fernö, A., Braithwaite, V., Kristiansen, T., 2013. Innovative behaviour in fish: Atlantic cod can learn to use an external tag to manipulate a self-feeder. Animal Cognition, 1-7.

Millot, S., Nilsson, J., Fosseidengen, J.E., Bégout, M.-L., Kristiansen, T., 2012. Evaluation of selffeeders as a tool to study diet preferences in groups of Atlantic cod (Gadus morhua). Aquatic Living Resources 25, 251-258.

Millot, S., Péan, S., Chatain, B., Bégout, M.L., 2011. Self-feeding behavior changes induced by a first and a second generation of domestication or selection for growth in the European sea bass, Dicentrarchus labrax. Aquatic Living Resources 24, 53-61.

Miyazaki, T., Masuda, R., Furuta, S., Tsukamoto, K., 2000. Feeding behaviour of hatchery-reared juveniles of the Japanese flounder following a period of starvation. Aquaculture 190, 129-138.

$\varnothing$ verli, $\varnothing$., Sørensen, C., Nilsson, G.E., 2006. Behavioral indicators of stress-coping style in rainbow trout: Do males and females react differently to novelty? Physiology \& Behavior 87, 506-512.

$\varnothing$ verli, $\varnothing$., Winberg, S., Damsård, B., Jobling, M., 1998. Food intake and spontaneous swimming activity in Arctic char (Salvelinus alpinus): role of brain serotonergic activity and social interactions. Canadian Journal of Zoology 76, 1366-1370.

Paspatis, M., Maragoudaki, D., Kentouri, M., 2002. Feed discrimination and selection in self-fed European sea bass Dicentrarchus labrax. Aquaculture Research 33, 509-514. 
Réale, D., Garant, D., Humphries, M.M., Bergeron, P., Careau, V., Montiglio, P.-O., 2010. Personality and the emergence of the pace-of-life syndrome concept at the population level. Philosophical Transactions of the Royal Society B: Biological Sciences 365, 4051-4063.

Réale, D., Reader, S.M., Sol, D., McDougall, P.T., Dingemanse, N.J., 2007. Integrating animal temperament within ecology and evolution. Biological Reviews 82, 291-318.

Rubio, V.C., Vivas, M., Sanchez-Mut, A., Sanchez-Vazquez, F.J., Coves, D., Dutto, G., Madrid, J.A., 2004. Self-feeding of European sea bass (Dicentrarchus labrax, L.) under laboratory and farming conditions using a string sensor. Aquaculture 233, 393-403.

Sánchez-Vázquez, F.J., Azzaydi, M., Martinez, F.J., Zamora, S., Madrid, J.A., 1998. Annual rhythms of demand-feeding activity in sea bass: evidence of a seasonal phase inversion of the diel feeding pattern. Chronobiology International 15, 607-622. .

Sánchez-Vázquez, F.J., Martinez, M., Zamora, S., Madrid, J.A., 1994. Design and performance of an accurate demand feeder for the study of feeding behaviour in sea bass, Dicentrarchus labrax L. Physiology \& Behavior 56, 789-794.

Sih, A., Bell, A., Chadwick Johnson, J., 2004. Behavioral syndromes: an ecological and evolutionary overview. Trends in Ecology \& Evolution 19, 372-378.

Silva, P.I.M., Martins, C.I.M., Engrola, S., Marino, G., Øverli, Ø., Conceição, L.E.C., 2010. Individual differences in cortisol levels and behaviour of Senegalese sole (Solea senegalensis) juveniles: Evidence for coping styles. Applied Animal Behaviour Science 124, 75-81.

Sneddon, L.U., 2003. The bold and the shy: individual differences in rainbow trout. Journal of Fish Biology 62 971-975.

Tian, X., Qin, J.G., 2003. A single phase of food deprivation provoked compensatory growth in barramundi Lates calcarifer. Aquaculture 224, 169-179.

Tveteras, R., Nystoyl, R., 2011. Fish production Estimates \& trends 2011-2012 Santiago, Chile. Verbeek, M.E.M., Drent, P.J., Wiepkema, P.R., 1994. Consistent individual differences in early exploratory behaviour of male great tits. Animal Behaviour 48, 1113-1121.

Wilson, D.S., Clark, A.B., Coleman, K., Dearstyne, T., 1994. Shyness and boldness in humans and other animals. Trends in Ecology \& Evolution 9, 442-446.

Wolf, M., Van Doorn, S., Leimar, O., Weissing, F.J., 2007. Life-history trade-offs favour the evolution of animal personalities. Nature, 581-585.

Yoshida, M., Nagamine, M., Uematsu, K., 2005. Comparison of behavioral responses to a novel environment between three teleosts, bluegill Lepomis macrochirus, crucian carp Carassius langsdorfii, and goldfish Carassius auratus. Fisheries Science 71, 314-319. 


\section{Figure legends}

\section{$627 \quad$ Figure 1}

628 Scheme and dimensions of the open field apparatus.

\section{$629 \quad$ Figure 2}

630 Relation between the "latency to emerge from the shelter" during the open field test (OFT) and the

631 "latency before the first escape attempt" during the restraint test. $\left(r_{s}=0.63, p<0.01\right)$.

\section{Figure 3}

633

634

635

636
Distribution of the values measured for the variables of interest during the duration of the OFT (20 min) with respect to individual percentage of actuation on the self-feeder device. A - Latency to emerge from the shelter $(s) ; r_{s}=0.53 ; p=0.02$.B - Time spent in the shelter; $r_{s}=0.54 ; p=0.02$. C - Mean distance from the shelter; $r_{s}=-0.55 ; p=0.02$. $D$-Time spent in central area; $r_{s}=-0.52 ; p=0.03$. 
Table 1 : Inter-individual variability for variables of interest in the open field and restraint tests. All values are presented as mean ( \pm sd) and range (min-

max) for each triggering category.

Behavioural test

Triggering category

Variables

Latency before first escape attempt (s)

Total escape duration (s)

Number of escape attempts

\section{Restraint test \\ HT \\ meantsd $(\min -\max )$ mean \pm Ld $(\mathrm{n}$}

$\begin{array}{llll}1.9 \pm 1.9 & (0.0-5.3) & 4.1 \pm 4.8 & (0.0-15.1)\end{array}$

$6.3 \pm 5.7 \quad(0.0-15.0) \quad 10.7 \pm 8.9$

(0.0 - 15.1) Time spent in shelter(s)

(0.0 - 27.0) Time spent in center area (s)

Time spent in border area (s)

Distance travelled (BL)

Mean distance to the shelter $(\mathrm{cm})$

Number of returns in shelter

\begin{tabular}{llll}
\multicolumn{4}{c}{ Open Field test } \\
\hline \multicolumn{2}{c}{ HT } & \multicolumn{2}{c}{ LT+ZT } \\
mean $\pm s d$ & \multicolumn{1}{c}{$(\min -\max )$} & mean $\pm \mathrm{sd}$ & \multicolumn{1}{c}{$(\min -\max )$} \\
\hline $594.5 \pm 409.4$ & $(145.0-1200.0)$ & $271.1 \pm 317.2$ & $(18.0-1066.0)$ \\
$468.9 \pm 270.9$ & $(106.2-791.3)$ & $233.3 \pm 251.5$ & $(4.8-653.8)$ \\
$95.0 \pm 150.1$ & $(0.2-427.9)$ & $171.7 \pm 184.1$ & $(15.1-526.8)$ \\
$317.5 \pm 242.1$ & $(0.6-647.8)$ & $488.2 \pm 315.7$ & $(64.1-1007.7)$ \\
$225.3 \pm 122.0$ & $(83.0-413.1)$ & $352.1 \pm 234.2$ & $(109.1-888.7)$ \\
$9.6 \pm 8.5$ & $(1.5-22.2)$ & $16.8 \pm 11.6$ & $(3.2-33.9)$ \\
$84.5 \pm 43.1$ & $(51.0-166.0)$ & $57.3 \pm 75.2$ & $(1.0-212.0)$ \\
\hline
\end{tabular}


Table 2 : Table of correlations between variables of interest of restraint test and open field test. Significant results are shown in bold characters and level of significance was $p<0.05$.

\begin{tabular}{|c|c|c|c|c|c|c|c|c|c|c|c|c|}
\hline & \multirow[b]{2}{*}{ Variables of interest } & \multicolumn{4}{|c|}{ Restraint test } & \multicolumn{7}{|c|}{ Open field test } \\
\hline & & $\%$ Manipulation & 1 & 2 & 3 & 1 & 2 & 3 & 4 & 5 & 6 & 7 \\
\hline \multirow{4}{*}{$\begin{array}{c}\text { Restraint } \\
\text { test }\end{array}$} & \% Manipulation & & $r s=0.38, p=0.10$ & $r s=-0.33, p=0.15$ & $\mathrm{rs}=-0.32, \mathrm{p}=0.17$ & - & - & - & - & - & - & - \\
\hline & 1: Latency before first escape attempt (s) & $r s=0.24, p=0.33$ & - & $r s=-0.81, p<0.01$ & $r s=-0.73, p<0.01$ & $r s=0.63, p<0.01$ & $r s=0.20, p=0.42$ & $r s=0.01, p=0.95$ & $r s=-0.23, p=0.34$ & $\mathrm{rs}=0.01, \mathrm{p}=0.95$ & $r s=-0.27, p=0.26$ & $r s=-0.04, p=0.8 s$ \\
\hline & 2: Total escape duration (s) & $r s=-0.19, p=0.44$ & - & & $r s=0.94, p<0.01$ & $r s=-0.23, p=0.37$ & $r s=-0.47, p=0.51$ & $\mathrm{rs}=0.27, \mathrm{p}=0.28$ & $r s=0.41, p=0.09$ & $\mathrm{rs}=0.01, \mathrm{p}=0.97$ & $r s=0.44, p=0.07$ & $r s=-0.15, p=0.54$ \\
\hline & 3: Number of escape attempts & $r s=-0.19, p=0.46$ & - & - & & $r s=-0.15, p=0.53$ & $\mathrm{rs}=-0.48, \mathrm{p}=0.04$ & $\mathrm{rs}=0.35, \mathrm{p}=0.16$ & $\mathrm{rs}=0.37, \mathrm{p}=0.13$ & $\mathrm{rs}=0.06, \mathrm{p}=0.81$ & $r s=0.42, p=0.09$ & $\mathrm{rs}=0.01, \mathrm{p}=0.97$ \\
\hline \multirow{7}{*}{$\begin{array}{l}\text { Open field } \\
\text { test }\end{array}$} & 1 : Latency to emerge from the shelter & $r s=-0.53, p=0.02$ & - & - & & - & $\mathrm{rs}=-0.02, \mathrm{p}=0.94$ & $\mathrm{rs}=0.20, \mathrm{p}=0.41$ & $\mathrm{rs}=-0.06, \mathrm{p}=0.79$ & $\mathrm{rs}=0.09, \mathrm{p}=0.72$ & $r s=-0.12, p=0.63$ & $r s=0.11, p=0.66$ \\
\hline & $2:$ In shelter duration $(\mathrm{s})$ & $r s=0.54, p=0.02$ & - & - & & - & - & $r s=-0.82, p<0.01$ & $r s=-0.69, p<0.01$ & $r s=-0.53, p=0.02$ & $r s=-0.90, p<0.01$ & $\mathrm{rs}=0.59, \mathrm{p}<0.01$ \\
\hline & 3: Time spent in center zone (s) & $r s=-0.51, p=0.03$ & - & & - & - & - & - & $r s=0.49, p=0.04$ & $r s=0.53, p=0.02$ & $r s=0.80, p<0.01$ & $r s=-0.36, p=0.14$ \\
\hline & 4: Time spent in border zone ( $\mathrm{s}$ ) & $r s=-0.26, p=0.29$ & - & - & - & - & - & - & - & $r s=0.26, p=0.30$ & $r s=0.75, p<0.01$ & $\mathrm{rs}=-0.60, \mathrm{p}<0.01$ \\
\hline & 5: Total distance travelled (BL) & $r s=-0.17, p=0.59$ & - & & - & - & - & - & - & - & $r s=0.52, p=0.03$ & $\mathrm{rs}=-0.09, \mathrm{p}=0.73$ \\
\hline & 6: Mean distance from the shelter $(\mathrm{cm})$ & $\mathrm{rs}=-0.55, \mathrm{p}=0.02$ & - & - & - & - & - & - & - & - & - & $\mathrm{rs}=-0.55, \mathrm{p}=0.02$ \\
\hline & 7: Number of returns to the shelter & $r s=0.36, p=0.14$ & - & - & - & - & - & - & - & - & - & - \\
\hline
\end{tabular}


Figure 1:

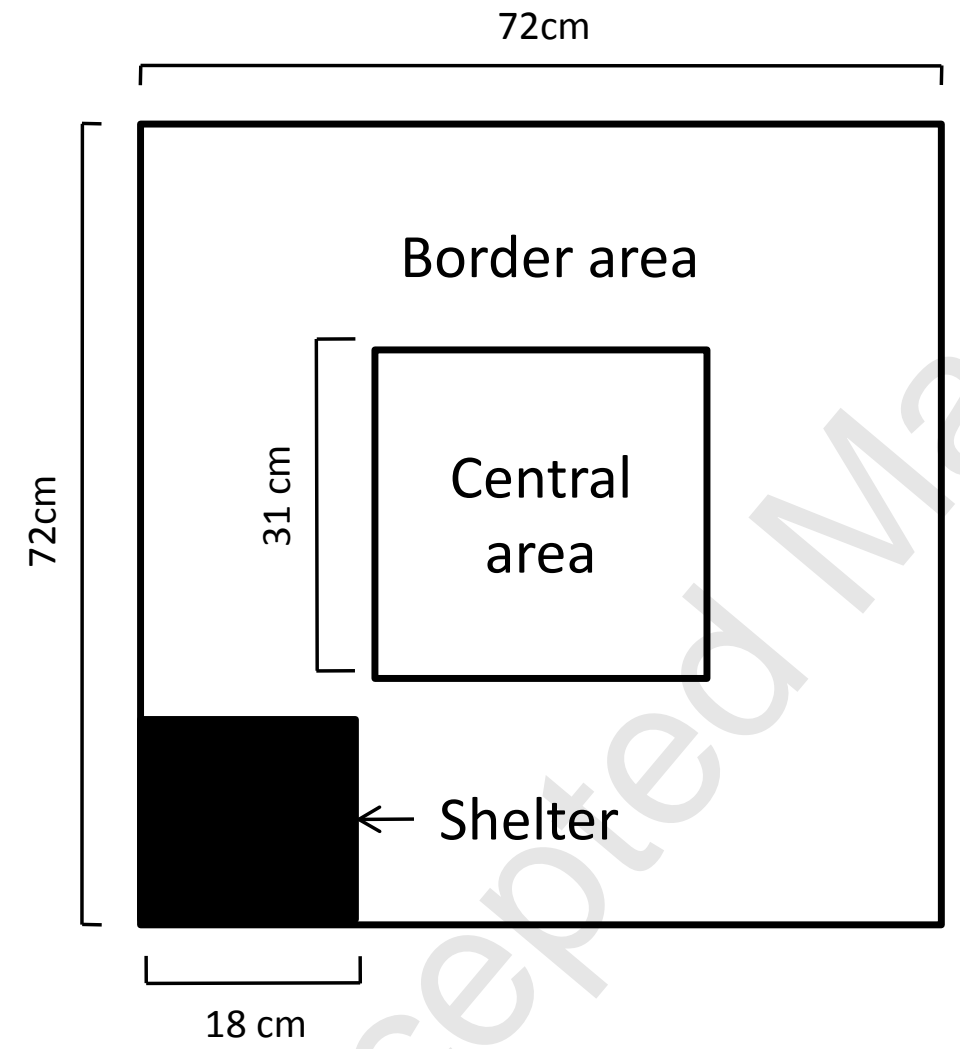


Figure 2:

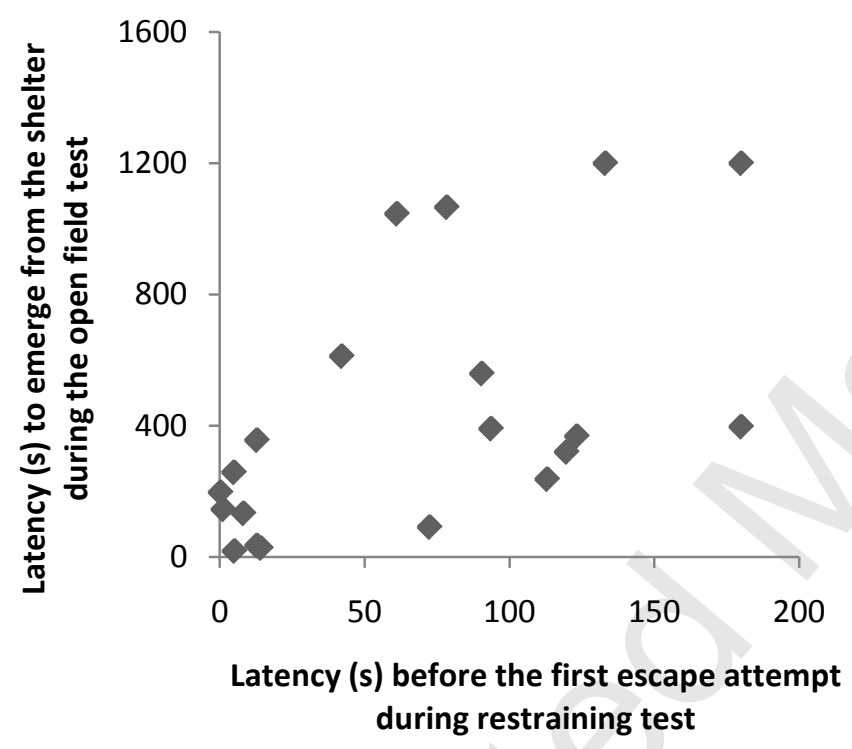


Figure 3:
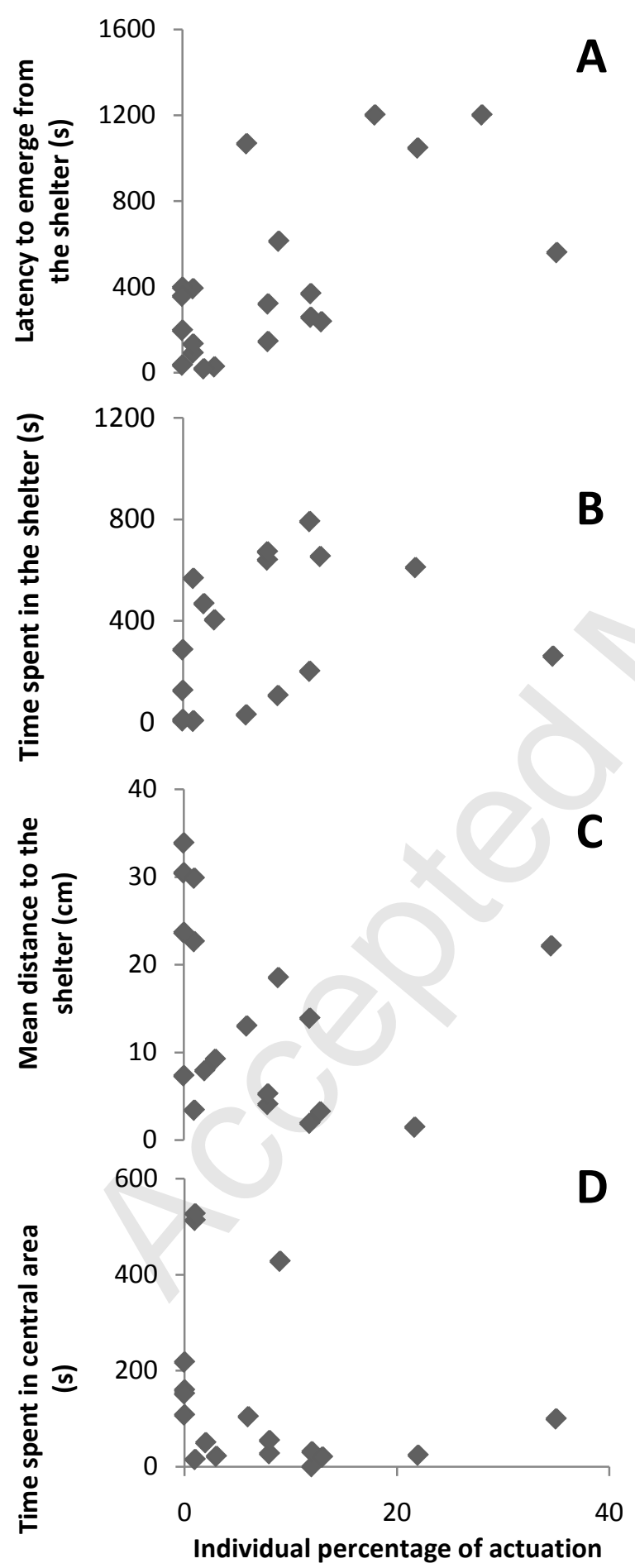